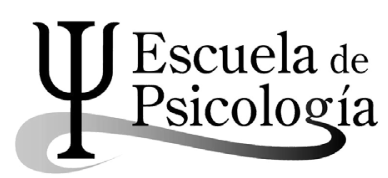

Wímb lu, Rev. electrónica de estudiantes Esc. de psicología, Univ. de Costa Rica. 9 (2): 45-59, 2014 / ISSN: 1659-2107

\title{
DEL ARTE A LA LOCURA Y DE LA LOCURA AL ARTE: LA EXPRESIÓN GENIAL DE LA PATOLOGÍA
}

From Art to Madness and from Madness to Art: The genius expresion of pathology

María Alejandra Varela Sandoval*

Luis Diego Villalobos Morera**

\begin{abstract}
Resumen: Cuando el arte se convierte en una locura hay una acción recíproca donde todo influye sobre un todo que es el artista en sí mismo, como un encadenamiento de procesos que llevan a la expresión genial. Este artículo es un acercamiento a la creatividad, psicopatología y la genialidad desde una construcción histórica de artistas concebidos como genios que han mostrado síntomas o características de desórdenes conductuales y emocionales como factor influyente en la expresión artística.
\end{abstract}

Palabras clave: arte, locura, genio, creatividad, expresividad, patología, artista.

Abstract: When art becomes madness, there is a reciprocal action where everything is influenced by all else which is the artist himself, as a sequence of processes that leads to brilliant expression. This article refers to an approach to creativity, psychopathology, and genius from a historical perspective about artists known as geniuses who have shown symptoms or characteristics of behavioral and emotional disorders as an underlying feature in their artistic expression.

Key Words: art, madness, genius, creativity, expressiveness, pathology, artist.

Universidad de Costa Rica, Escuela de psicología, Costa Rica. Correo: alejandravarelasandoval@ gmail.com

** Universidad de Costa Rica, Escuela de psicología, Costa Rica. Correo: Idiegovm@yahoo.com Recepción: 23/5/2013 Aceptación: 30/10/2013 
“...los gigantes del genio pagan por su potencia intelectual con la degeneración y la locura.”

C. Lombroso

\section{Introducción}

Más que una expresión común, el "artista loco" se ha vuelto una construcción social consolidada, la cual dicta que la locura o trastorno mental es algo inherente al proceso creativo e innovador que realizan los autores de distintas formas de arte, entre ellos pintores, músicos, poetas, etc. Por tanto, es importante cuestionarse qué hay detrás de esta asociación popular y cómo conviven la locura y el arte en un mismo ser. Para esto es necesario el cuestionamiento sobre el valor íntegro de esta asociación dentro de la concepción de genio.

Se presenta el arte como una vía expresiva para los alienados en manicomios, comoun lenguaje al que muchos psiquiatras prestan atención y consideran una comunicación exitosa entre médico y paciente, como lo reconoce Walter Morgenthaler, psiquiatra que estuvo a cargo del conocido caso de Adolf Wölfli, (1864-1930) quien padeció mentalmente. Gracias a su trabajo, Morgenthaler logra desarrollar una novedosa técnica de diagnóstico (Puente, 2010).

\section{Genio ¿Creador involuntario o loco?}

De acuerdo con Aragón (2009) el entendimiento actual de genio es resultado de un proceso que tiene raíces desde el romanticismo. Los románticos recogen un elemento de irracionalidad del entusiasmo lírico desarrollado por Platón $-y$ conservado hasta la actualidad- que atribuye un furor religioso o de origen divino al don poético.

Hoy, no solo se considera genio a quien haga poesía, también a otra clase de creadores; es por esto que existe una inevitable asociación entre creatividad y genialidad, ambos con la posibilidad de desarrollarse en muchos ámbitos pero con especial brillo en el arte.

Considerar a un creador no poeta como genio era una extrapolación impensable en Grecia y Roma por la jerarquía social existente. Esta cultura responde con gran desvalorización al trabajo manual y lo determina como una ocupación solo para esclavos, "...ya que la lengua se impone a la mano" (Aragón, 2009, p. 255) ubicaba al artista plástico en un peldaño inferior al poeta. Además, la situación económica imposibilitaba el nacimiento de un genio obsesionado por la búsqueda de originalidad en sus creaciones pero, lastimosamente ignorado por sus contemporáneos, como sucede en la actualidad. Es decir, estos rasgos distintivos de la persona genial caracterizan a los románticos y a los modernos. Como señala el mismo autor "...cuando el Renacimiento toca a su fin, se advierten 
signos de una incipiente representación del individuo en el romanticismo y con la que estamos tan familiarizados" (p. 256).

Partiendo de la concepción del genio como creador se debe diferenciar éste del talentoso, aunque ambos pueden tener frutos asombrosos no pasan por el mismo camino para llegar a ellos. Jurgen Meyer (1875, citado en Lombroso, 2008) dice que el talento se conoce a sí mismo y sabe por qué y cómo llega a una teoría, mientras que el genio no lo sabe, él realiza estos procesos ignorando el cómo y el porqué de su accionar, solo llega a una teoría de forma espontánea porque "... no hay nada más involuntario que la idea genial" (p. 81).

Comúnmente se considera que el genio representa el hiperdesarrollo de las capacidades humanas, con un carácter de superioridad y una excelencia que muchas veces tiene lugar en una especificación.

La teoría de la degeneración indica que la variación individual de genio no es siempre una anormalidad, aunque varíe en comparación con la media no representa una suspensión sino un grado más avanzado de humanización (Lombroso, 2008).

A pesar de que esta teoría de la neurosis degenerativa como base del genio cause cierta resistencia o rechazo, se puede asimilar más fácilmente si se piensa en degeneración como término zoológico que hace referencia a las ventajas que se han perdido ante otros animales: los simios tienen más músculos y una cola, los reptiles tienen más costillas y más vertebras, etcétera (Lombroso, 2008).

Los humanos han perdido estas ventajas pero se compensan con un gran desarrollo en otra dirección, como los procesos psicológicos superiores; es decir: "así como los gigantes en estatura pagan su grandeza con la esterilidad y con una relativa debilidad intelectual y muscular, los gigantes del genio pagan por su potencia intelectual con la degeneración y la locura" (Lombroso, 2008, p. 80).

La potencia precoz es otro rasgo característico del genio que se muestra en distintos ámbitos según la especificación de las ideas geniales, como también sucede en "el loco" principalmente con la locura moral, la cual, según el mismo autor, se caracteriza por la originalidad excesiva, desproporciones psíquicas por el desarrollo en algunas facultades y otras rezagadas, el abuso de símbolos como modo exclusivo de expresarse, entre otras. Y no casualmente una tendencia muy presente en el arte de los locos es la riqueza de símbolos y el uso de distintos recursos para reforzar ideas que no se pueden decir solo con un pincel o solo con un lápiz. Un ejemplo claro de un artista precoz y genial es Mozart dando conciertos desde los 6 años de edad, o el caso de algunos megalómanos que acostumbran a expresar sus ideas mediante un lenguaje distinto al que utiliza típicamente el humano.

Las ideas geniales y los impulsos de los locos son tan espontáneos, así como involuntarios, que surgen de golpe. Lombroso (2008) indica que los más importantes conceptos de los pensadores estallan de golpe o se desarrollan 
por cerebración inconsciente, al igual que los actos impulsivos de quien padece mentalmente; pero no solo esto los une, en muchos casos se dice que tanto el genio como el loco mantienen una "relación fría" con los demás y se alejan de los afectos y las convicciones sociales. Esta última característica se convierte en un pilar cuando es llevada al arte, en el sentido que permite la creación de un arte crítico y sin interés de cumplir con dichas convicciones, contribuye así a la función del artista dentro de la sociedad como denunciante de las problemáticas sociales y la presentación de una nueva corriente artística, diferente a la tradicional en su momento. Tal es el caso de Friedrich Nietzsche quien escribe: "Actuar contra su tiempo y, de esa manera, sobre su tiempo y, espero, a favor de un tiempo por venir" (citado en Guerreo, 2007, p. 11).

Prinzhorn (1966) detectó seis pulsiones básicas en las pinturas de los esquizofrénicos, considerados como el tipo de psicóticos más productivos en el campo de la creación y las plasmó en un libro que fue mal visto por sus colegas, excepto por Sigmund Freud (Bolaños, 2007) las pulsiones fueron: hacia la expresión, el simbolismo, el juego, la ornamentación compulsiva, el orden pautado y la copia obsesiva.

No por casualidad se asocia al artista como loco, han sido muchas las opiniones emitidas que hacen referencia a esta representación, por ejemplo la de Flaubert (1889, citado en Lombroso, 2008)

El artista, en mi opinión, es una monstruosidad, algo fuera de la naturaleza; todas las desdichas con que le acucia la Providencia le vienen de la testarudez con que niega este axioma: por ello sufre y hace sufrir. Interroguen si no sobre ello a las mujeres que han amado a poetas y a los hombres que han amado a actrices (p. 81).

Desde esta arista temática, se puede rescatar la visión sintetizadora de arte y locura, pues ha sido una creencia popular la relación entre estos tan tergiversados conceptos; al respecto, Gómez (2005) apunta hacia una perspectiva más exacta haciendo referencia a un estudio realizado por la Asociación Americana de Psiquiatría, exponiendo entonces la posibilidad, ahora más racional, de que la creatividad y el arte hacen más factible el desarrollo de trastornos mentales; el estudio versa: "...las personas sanas ligadas al mundo de la creatividad tienen más posibilidades de padecer un trastorno mental que las que no tienen ninguna relación con las artes (poetas 50\%, músicos 38\%, pintores 20\%)" (p. 45).

Por otra parte, la creatividad artística no solamente puede funcionar como facilitadora del desarrollo de trastornos, también puede aparecer durante el desarrollo de estos, y por esto algunas personas con esquizofrenia crean obras extraordinarias mientras su estructura psíquica sufre. Gómez (2005) expone que desde el psicoanálisis la esquizofrenia destruye el yo como estructura psíquica.

Jung, como un precursor en cuanto a la importancia del arte como proceso más que como un fin en sí mismo, creía que era el transcurso del arte lo que le 
daba más energía y ánimos a la persona para resolver dificultades específicas, más que una simple idea o aclaración por parte del analista. Gómez (2005) cita a Jung al escribir: "...si una obra de arte se explica por el mismo procedimiento que una neurosis, entonces, o bien la obra de arte es una neurosis, o bien la neurosis es una obra de arte." (p.6) Partiendo de lo anterior, se denota la significancia de la corriente artística dentro de un páramo psicológico.

Tomando en cuenta este último aspecto, Lombroso (2008) analiza al arte en un punto histórico y social, y lo entrelaza a una visión de locura artística, en este sentido, el artista es considerado un "loco" y sus obras su medio de expresión usado para comunicar al mundo lo que piensa. Este autor plantea incluso el arte como una patología, por lo que elementos como "...la preponderancia exagerada de un cierto color (...) la indecente lascivia y el propio exceso de originalidad forman parte de la patología del arte" (p. 82).

En su artículo, Lombroso (2008) escribe una reseña sobre cómo la locura juega un papel significativo en los parámetros artísticos, haciendo notar un lenguaje tal que se consideraría como atavismo, también expuesto en cuadros y pinturas; este autor enfatiza que para algunos pintores la perspectiva falta completamente, sin embargo, la forma y estilo logran un efecto cautivante. Siguiendo con su propuesta de patología artística, incluye a la música en este análisis, utiliza el caso de Donizetti para ejemplificar cómo sus sinfonías coincidían con sus accesos maniacos.

...Donizetti, en estado de demencia terminal, ya no percibía sus melodías predilectas; y sus últimas óperas desprenden ya esa influencia fatal, que los críticos han señalado también en la sinfonía de La novia de Messina de Schumann, compuesta durante sus accesos maníacos (Lombroso, 2008, p.83).

Desde esta visión patológica, Romo (1998) expone acerca de teorías relacionadas a la creatividad, entre ellasla teoría de creatividad y arte como trastorno psicológico; en esta trata la visión psicoanalítica del arte como finalidad catártica en el artista; sin embargo, se mantiene un atisbo de locura en aquellos artistas que, desde el psicoanálisis, intentan "...escarbar en su yo profundo, la raíz de su creatividad personal (...) y temen someterse a terapias por el miedo a acabar así con la fuente de su potencial creador" (p. 21). Se nota aquí una concientización de la locura dentro de la habilidad creativa.

\section{Creatividad}

Se encuentran muchas aproximaciones teóricas que no precisamente coinciden en una misma definición del concepto de creatividad. Este elemento que puede ser visto como rasgo humano, es un tema ambiguo y con mucha literatura al respecto. Por ejemplo, Pascale (2005) presenta la creatividad como 
un proceso socio-cultural, pues es algo existente más allá de las cabezas de las personas, para ello utiliza la definición de Csikszentmihalyi, que propone la creatividad como el resultado de un interaccionismo entre una cultura, una persona novedosa y un grupo de expertos que hacen válida la innovación. Esta innovación se integrará entonces a la cultura general y pasará a ser un aporte a la evolución en este aspecto.

Por otra parte, Álvarez (2010) define la creatividad como "...un proceso del pensamiento, un mecanismo intelectual a través del cual se asocian ideas o conceptos, dando lugar a algo nuevo..." (p. 5) es decir, una búsqueda de soluciones nuevas. Entonces, se puede ver la creatividad como un proceso innovador que no se desarrolla a gran escala, exclusivamente en todas las personas.

Eisner (1995, citado en Morales, 2001) considera que el pensamiento creativo tiene por sí mismo una ruptura de límites; es decir, cuestiona lo establecido y lo dado culturalmente como normal en su contexto histórico, tal como en el arte existe el periodo modernista, que representa casi al pie de la letra la ruptura antes expuesta. Se denota entonces la originalidad como característica del artista; sin embargo, para que esta ruptura sea considerada creativa, debe generar soluciones al problema que facilitó dicha ruptura inicial.

En esta guía de conceptos se debe agregar el de pensamiento creativo, que se relaciona con la creatividad en el sentido de crear o modificar algo de una forma novedosa, se producen en el individuo nuevas ideas para desarrollar o modificar algo ya existente. La importancia radica en que las personas pueden conocer su pensamiento creativo para así implementar y utilizar nuevas ideas en distintas áreas (Waiburd, 2009).

Morales (2001) propone características propias del pensamiento creativo, entre ellas menciona la ampliación de límites como una capacidad para romper con lo esquematizado y brindar un nuevo uso de ello, para lo cual el individuo cuenta con la invención, que es justamente lo que le da la capacidad de asociar y transformar lo conocido en algo novedoso.

Dentro de lo novedoso como parte del pensamiento creativo, se debe aclarar que no todo lo novedoso es algo creativo; para ello se retoma a Tatarkiewicz (1992) al escribir acerca de la novedad representada en: "...nuevas concepciones y no cada nueva organización que surja; únicamente las creaciones de los talentos superiores; aquellas que tienen unas consecuencias de gran alcance" (citado en Morales, 2001, p. 43).

\section{Contexto, entorno y creatividad}

Como en todo lo humano es necesario tomar en cuenta la influencia social en tanto constituyente; es complejo tratar la creatividad sin incluir factores como el contexto determinado en el que surge. La respuesta de los estudiosos ante 
esto no ha sido inexistente, Pascale (2005) escribe sobre la dialéctica entre "... sociedades con superávit o pobres, de diversidad cultural o aislamiento, etc." ( $p$. 71) y la persona creativa.

También para Morales (2001) el contexto en el cual se produce la creatividad es un factor determinante para su desarrollo en términos sociales, familiares, culturales y personales; el individuo en su debida interacción con el entorno utiliza caracteres muy propios, como la experiencia y el potencial cognitivo, que como se sabe, estas no son las mismas para todos los seres humanos.

Existe la necesidad de analizar el proceso artístico de acuerdo con la globalidad que lo caracteriza como un proceso comunicacional (esto quiere decir que el arte no acaba con la creación artística) en el que no sólo existe un emisor sino también un mensaje, un código, un canal y un receptor activo, como señala García Canclini (1977) y con esto se hace énfasis en la concepción histórica de receptor pasivo, deslumbrado por la creación artística y en acto solemne de contemplación.

Es posible definir el arte en todas sus manifestaciones como una imagen de la cultura. Este mismo autor propone el tripe relativismo (cultura, historia y clase social) y sintetiza sus objetivos de la siguiente manera: "se trata de descentralizar el estudio del arte de la obra, o de una Belleza idealizada, y pasar a analizarla como un proceso social y comunicacional." (García, 1977, p. 12).

Desde esta perspectiva, el proceso artístico se torna mucho más complejo, no lineal y revolucionario por disputar las bases de una estética estática desde la cual se ha valorado el arte históricamente.

\section{La comunicación y expresividad en el arte}

En un aspecto de fin y medio, Romo (1998) trata el arte como un medio de comunicación, analiza esto desde la pintura por ser un reflejo gráfico de un mensaje social o emotivo, comenta el autor acerca de cómo el arte es "...un instrumento cuyo sentido trasciende personalmente al artista (...) y se sitúa en el espectador." (p. 22) es decir, el mensaje artístico se convierte en un lenguaje que sobrevive aún sin su creador, pues sintetiza su sentido inicial y lo transmite a quien recibe la obra en sí; se presenta entonces el caso de Van Gogh y de muchos más que consideraban el arte como la transmisión de sus sentimientosal pintar el lienzo, y así conmover espectadores con sus cuadros.

Horst Nitschack (1991) expone acerca de la "Teoría de la Recepción"1y su concepción como una respuesta ante la problemática del aislamiento de una obra literaria de su respectivo contexto, mismo problema que se puede analizar en distintas manifestaciones artísticas y por ende, de sus creadores, que también forman parte de un contexto algunas veces obviado. De igual manera se rescata la importancia del espectador para la existencia de cualquier obra de arte, pues 
desde la teoría de la recepción, el receptor del mensaje es a su vez creador, esto en un sentido dialéctico pues el artista es el primer público de su propia obra a la vez que lo ha sido de otras tantas previas a su creación.

A modo de ejemplificar la relevancia de esta teoría en aplicación concisa desde un artista, se presentan unas líneas escritas directamente por Julio Cortázar, expuestas por Ricardo Bada (2013) desde la reedición del famoso libro Rayuela en su 50 aniversario por ALFAGUARA (Bernárdez, Álvarez, 2012) En 1960, Cortázar escribe a su amigo Jean Barnabé:

Escribo mucho, pero revuelto. No sé lo que va a salir de una larga aventura a la que creo aludí en alguna otra carta. No es una novela, pero sí un relato muy largo que en definitiva terminará siendo la crónica de una locura. Lo he empezado por varias partes a la vez, y soy a la vez lector y autor de lo que va saliendo (párrafo 5).

A partir de estas últimas líneas, Cortázar demuestra a la perfección el sentido reciproco del crear arte mediante la exposición del arte mismo; ahora bien, es aquí donde se denota la trascendencia de las obras por abarcar más allá de la historicidad que ha valorizado el arte como algo estático, sin capacidad de trascender en sus respectivos espectadores.

Toda expresión artística tiene grandes poderes comunicativos, indiscutiblemente; el caso de Adolf Wölfli, mencionado en la introducción de este artículo, es un ejemplo claro de este factor comunicativo del arte en personas con trastornos mentales, pues como relata Puente (2010) las obras de Wölfli fueron inicialmente un experimento por parte de su psiquiatra Walter Morgenthaler; sin embargo, esta colección se ha convertido en todo un clásico del arte moderno con más de 25.000 obras en su haber.

Peiry (2006) relata sobre la corriente artística denominada Art Brut, que nace del pintor y escultor Jean Dubuffet alrededor de 1945, en este año explora la calidad pictórica y artística de los enfermos aislados en un manicomio utilizando el arte como medio de expresión, estas obras "...surgen de la exclusión y del enclaustramiento (...) el asilo psiquiátrico." (p. 19) Peiry presenta el internamiento como un secuestro y una privación, aunado a ello, el estar aislado, recluido, inactivo y oprimido, provoca en los enfermos un letargo que prolifera su imaginación y su creatividad.

\section{Artistas: ¿canalizadores de locura o verdadera salud mental?}

Dentro del siglo XX la locura tuvo alto nombre y una gran documentación, tanto las obras como la vida personal de los artistas fueron expuestos a un efecto de incomprensión y turbulencia en cuanto a la mirada social de la época; sin embargo, el artista loco no es igual al loco ordinario, esta condición le brinda 
al arte una doble visión de carácter platónico al hablar de locura clínica y locura creativa (Quirosa, 2007).

A continuación se plantea una construcción histórica en la que se mencionan algunos genios creadores que han pasado a la posteridad a pesar de una "anormalidad" conductual, psicológica, afectiva y expresiva, siguiendo un patrón de "locura" dentro del arte como manifestación socio-cultural.

Vincent Van Gogh (1853-1890) fue un pintor postimpresionista cuya vida estuvo llena de situaciones humanamente conmovedoras expresadas en sus cuadros y su particular forma de ver el mundo; no se sabe aún con certeza cuál fue la causa concreta de la enfermedad que lo acompañó a través de su vida (pero su cuadro patológico sí revela un orden digno de una psicosis) su personalidad es descrita como "no agradable" y parece enfocarse más en pintar que en cualquier otra cosa, su padre argumenta: "...es lamentable que no sea más tratable, no se puede cambiar el hecho de que es un hombre extraño." (Van Gogh, citado en Konrad, 2001, p. 3).

Konrad (2001) recuerda el hecho acontecido el 23 de diciembre de 1888, cuando Van Gogh se corta una de sus orejas y la lleva a una prostituta, ese mismo día es internado al hospital de Arles para dar inicio a una serie de visitas continuas a instituciones de este orden siendo la más considerable en Saint Remy, un hospicio para enfermos mentales que prefirió al servicio militar. Su vida termina en un suicidio mediante un disparo el 27 de julio de 1890, en presencia de su hermano y confidente Theo.

Francisco de Goya (1746-1828) pintor y grabador español, vive sumergido en un estado de bipolaridad cíclica; crea las Pinturas Negras en una etapa que vivencia con fuerza su patología en la que dice intuir el destino oscuro a través de "...frecuentes dolores cerebrales desde hacía dos décadas..." (Martín, s.f., p. 3). Es importante recalcar que Goya sufre durante el periodo de 1819 a 1923 un estado depresivo que lo hace incluso retirarse del mundo social y a concentrarse más en su trabajo.

Siguiendo a Jiménez (2012) Goya reunía en sumo grado la personalidad creativay durante las fases depresivas más notables, logra hacer catarsis de su sufrimiento y a través de la expresión de altos contenidos emocionales en sus múltiples producciones de tipo pictórico.

En cuanto a la música como una expresión artística per se; Morales y Comino (2007) escriben a manera de recopilación, una serie de músicos que presentaron características o cualidades de locura. Ellos exponen que determinados intérpretes y compositores a lo ancho de la historia han mostrado comportamientos irracionales que se recuerdan como síntomas de graves padecimientos mentales.

Ludwig Van Beethoven (1770-1827) sufrió una serie de contrariedades que alteraron su vida emocional y psicológica, el alcoholismo de su padre, la muerte de su madre, y su frustrante sordera progresiva. En 1817 esta incapacidad es casi 
insoportable para el músico pues en esta época no distinguía los sonidos e incluso las voces eran difíciles de identificar y definir; este personaje histórico sintió en esta etapa de su vida y posteriormente una irascibilidad y una inestabilidad mental muy notables, así como una enajenación mental también muy marcada que no impidió sus geniales creaciones musicales (Morales y Comino, 2007).

Por otra parte el músico y compositor alemán Robert Schumann, quien vivió entre 1810 y 1856, ha sido una de las historias más contadas a través de textos y películas, así como sujeto de variadas investigaciones, esto debido a su trágica y curiosa historia que presenta múltiples rasgos de patología a lo largo de su vida; marcada por crisis emocionales episódicas y depresiones constantes, así como obsesiones e intentos de suicidio; su vida finalmente termina en un hospital psiquiátrico en Enderlich. Entre los detalles más significativos en Schumann se encuentran las alucinaciones visuales y auditivas, dictados angelicales de melodías en las que sobresale la nota La y su famoso intento de suicidio arrojándose al Rhin; todo a raíz del sufrimiento y la tortura que le provocan sus episodios atribuidos a un trastorno bipolar o psicosis maniaco-depresiva (Morales y Comino, 2007).

Ahora bien, siguiendo a Morillo, Moreno y Rodríguez (2009) la pintura constituye una vía de escape en relación al dolor, la soledad, la enfermedad y la muerte cuando se habla de Edvard Munch (1863-1944). Este artista noruego dedicó su obra pictórica a expresar el sentir que predominaba en él a partir de la muerte de su madre, su hermana y su padre en tiempos no muy distantes; vivió con una marcada personalidad introspectiva y sombría, incluso preceden variadas enfermedades para referirse a él; tales como: temperamento melancólico, síndrome ansioso-depresivo, fobia social, agorafobia, neurosis y hasta esquizofrenia. Sin embargo, lo único que sí se puede constar es la influencia de su estado mental dentro de su obra en general y la manera de transmitir su estado interno a través de pinturas de forma tan innovadora de acuerdo a su época e incomprendido como la mayoría de la población de genios históricamente recordados.

De igual manera Salvador Dalí (1904-1989) es un gran exponente de comportamientos categorizados de "locura" y de una técnica muy expresiva en la pintura y en las artes plásticas en general. El surrealismo como movimiento artístico juega un papel importante en Dalí. Según Rodríguez (2004) utilizó esta técnica para expresar lo que sentía en su interior y así satisfacer sus necesidades materiales; este autor plantea desde su psicobiografía daliniana, la existencia de un trastorno psicótico en el pintor, pues en su autobiografía (obra artística en contenido literario) Dalí asegura y relata acontecimientos ocurridos en su etapa intrauterina.

Fernández (s.f.) coloca a Dalí no solo como un pintor sino como un artista dentro de diversas áreas y rescata su creación del curiosamente llamado: "método paranoico-crítico", un sistema irracional e innovador desde el que trata la pintura como una imagen en movimiento desde la cual simula las imágenes que emergen desde el inconsciente. Dentro de esta misma atmósfera psicoanalítica, 
Fernández recuerda que para Freud la obra de Dalí es una representación de sus obsesiones. Este innovador pintor español da un gran paso social al considerar la locura como parte de un marco de normalidad e influyente para que se pueda dar un proceso creativo.

Los casos de artistas menos reconocidos como Hugo Wolf (1860-1903) quien sufrió una crisis depresiva en 1895, seguida de una locura severa, y que si bien es cierto sorprendentemente logró recuperar su cordura, hacia finales de su vida sufrió otra gran crisis que terminó en una parálisis total, estado en el que murió. El compositor checo Bedrich Smetana (1824-1884) padeció de una sífilis que culminó en una sordera, durante este periodo fue acosado por sonidos agudos que impedían su actividad de composición, murió internado en un manicomio en Praga. En el caso de Manuel de Falla (1876-1946) se habla de una obsesión constante que lo llevó a episodios de alucinación y crisis nerviosas; su obsesión fue tal que se prohibía a sí mismo tomar agua sin ser hervida previamente. Para mencionar un último caso se habla de Sergei Rachmaninov (1873-1943) víctima de graves crisis mentales debido a fuertes críticas y a una mentalidad muy compleja que,al no podercon tanto, cayó en un descuido y abandono personal; gracias al neurólogo Nicolai Dahl, Rachmaninov pudo continuar con su obra musical y su vida (Morales y Comino, 2007).

Zurbano (2007) retoma a Freud para exponer la manera en que el arte exterioriza lo reprimido en la vida del creador o artista, así también la obra final transpone las fantasías inconscientes de quien lo crea, saca a la luz lo traumático y elabora al mismo tiempo una simbología tan personal como ninguna otra. Además, Lacan fundamenta al arte como un mediador entre el trauma del artista y el artista mismo. Sea cualquiera la perspectiva, es innegable la dinámica del arte en un plano de carácter psicológico en la persona que lo lleva a la expresión y lenguaje.

Edvard Munch dijo alguna vez: "Enfermedad, muerte y locura fueron los ángeles negros que velaron mi cuna y desde entonces me han perseguido durante toda mi vida" (citado en Morillo, Moreno y Rodríguez, 2009) haciendo referencia a su obra y expresión artística como melancólica y sublime. Al igual que Munch, la historia ha visto pasar a muchos otros artistas que han experimentado una explosión de creatividad en crisis de algún trastorno mental.

Esta pequeña muestra de personajes destacados en la historia es un reflejo de la relación existente que no permite disociar la degeneración mental con la genialidad artística.

\section{Psicopatología de la expresión}

Gómez (2005) señala que "El arte, al igual que el genio, son el resultado de múltiples componentes que siempre conservarán una parte del misterio" (p. 4). 
Grandes pensadores de la historia no han hecho caso omiso a este misterio, como Cesare Lombroso, Aristóteles, entre otros.

También Benjamin Rush (1812) creía que la enfermedad puede desarrollar talentos magníficos y funciones mentales, comparaba a la enfermedad con un terremoto que al agitar la tierra logra expulsar espléndidos fósiles (Gómez, 2005). $Y$ estas genialidades desde siempre fueron inevitablemente relacionadas con características extraordinarias de carácter mental. En su texto el Problema XXX, Aristóteles se cuestionaba el por qué las personas excepcionales eran con tanta frecuencia melancólicas (Gómez, 2005).

También otros autores de la disciplina psicológica han escrito sobre cómo se involucra el arte y el funcionamiento psicológico, por ejemplo: Jung fomentó la producción artística como parte del proceso terapéutico. Sin embargo, hay otras posiciones disyuntivas de esta relación como la expuesta por Gómez (2005) quien afirma que se ha demostrado que "...aunque talento y enfermedad pueden coincidir en una misma persona, no significa que se refuercen mutuamente" (p.7).

\section{¿Qué sucede con la creatividad cuando el sujeto enferma?}

Según Miller y sus colaboradores (1996, citado en Chávez y Lara, 2000)

...informaron acerca de tres casos de pacientes que iniciaron su trayectoria artístico-pictórica después de haber iniciado con un cuadro de demencia frontotemporal, y lograron una mayor productividad artística durante los estadios temprano y medio de su enfermedad (p.5).

Estos investigadores concluyeron que el funcionamiento de los lóbulos temporales y parietales permiten a que los pacientes planeen y ejecuten una obra artística, pero, sugieren que se deben realizar más estudios que faciliten una mejor comprensión de la relación entre las cortezas temporal anterior y visual en función del proceso visual en la creatividad (Chávez y Lara, 2000).

Dowker y su equipo (1996) indican que algunos pacientes que tienen déficits cognitivos, de comunicación o sensoriales, ciertamente llegan a ser muy buenos en campos específicas como la música y el dibujo, y desarrollan grandes habilidades con los números y tienen una buena memoria (Chávez y Lara, 2000).

\section{Conclusiones}

El arte y la locura no se pueden estudiar por separado cuando están en un mismo ser, como lo hacía la física estudiando el sonido, el calor, el magnetismo, la electricidad, etc. como fenómenos que no tienen relación entre ellos. El "fijismo" no puede ser parte del análisis de la patología en el arte. 
Como diría Hegel (citado en Politzer, 1975) nada está aislado, todo depende de todo, por esto cuando el arte se convierte en una locura hay una acción recíproca donde todo influye sobre un todo que es el artista, como un encadenamiento de procesos que llevan a la genialidad; así es como el arte importa más como proceso que como un fin en sí mismo, y merece una apreciación que trascienda la estética estática y se aproxime más a la perspectiva dialécticaporque decir dialéctica es decir movimiento (Politzer, 1975).

El arte y la locura fluyenen perfecta armonía con la persona, ser cambiante que al igual que lo que llaman locura, puede expresarse genial y psicopatológicamente. Robert Schumann y Edvard Munch son ejemplos de artistas reconocidos que conocieron, experimentaron y transmitieron el dolor que vivieron a través de su arte, y cuyas manifestaciones artísticas traspasaron su obra y se reflejaron en su forma de vida: Schumann recibiendo dictados angelicales de música y Munch muriendo en soledad rodeado de los cuadros que le recordaban la muerte de sus familiares, depresiones y alucinaciones.

Finalmente, se retoma a Gómez (2005) quien señala que a pesar de todas las teorías e investigaciones realizadas en este tema, siempre se conservará un halo de misterio e incertidumbre que crean y brindan un aspecto más magnético en cuanto a arte y locura se refiere, sin importar el por qué sino el cómo se lleva a cabo una obra de arte.

\section{Referencias bibliográficas}

Álvarez, E. (2010). Creatividad y pensamiento divergente. Desafío de la mente o desafío del ambiente. Recuperado de: http://www.interac.es/adjuntos/ crea_pensa_diver.pdf

Aragón-González, L. (2009). Reseña de El genio. Génesis de un concepto de Edgard ZILSEL. Revista de la Asociación Española de Neuropsiquiatría, 29, 255-256.

Bada, R. (2013). Rayuela. Primer medio siglo. En La Jornada Semanal el 16 de Junio de 2013. Recuperado el de http://www.jornada.unam.mx/2013/06/16/ sem-bada.html

Bolaños, M. (2007). El arte que no sabe su nombre. Locura y modernidad en la Viena del sigloXX. Rev. Asoc. Esp. Neuropsiq., XXVII(100), 445-464. Recuperado de: http://scielo.isciii.es/pdf/neuropsiq/v27n2/v27n2a14.pdf

Chávez, R. Carmen, M. (2000) La creatividad y la patología. Salud mental, 23(6). Fernández, M. (s.f.). Salvador Dalí y el psicoanálisis, (de Galo a Gala). Recuperado de: http://intercanvis.es/pdf/21/Salvador_Dali.pdf 
García, N. (2005). La antropología urbana en México. México D.F.: Fondo de Cultura Económica.

Gómez, J. (2005). Psicopatología de la expresión. Proyecto de investigación. Titulado Universitario Senior. Recuperado de: http://mayores.uji.es/ proyectos/proyectos2005/psicopatologiadexpres.pdf

Guerrero, J. (2007). Fragilidad e infraleve. Miche Foucault y Marcel Duchamp. Revista de arte y estética contemporánea. Julio/Diciembre Vol. XI. Recuperado de: http://www.saber.ula.ve/bitstream/123456789/20522/2/articulo7.pdf

Jiménez, F. (2012). Goya: Correlaciones en su patiobiografía. La comunicación a través del arte. Avances en Salud Mental Relacional, 11 (1). Recuperado de: http://www.psiquiatria.com/bibliopsiquis/handle/10401/5497

Konrad, W. (2001). La enfermedad psíquica de Vincent Van Gogh. En Alcmeon. Revista Argentina de Clínica Neuropsiquiátrica. Recuperado de: http:// ideasapiens.blogsmedia.com/psicologia/clinica/la_\%20enfermedad_ psquica_v.\%20van\%20gogh.htm

Lombroso, C. (2008). Arte, genio y locura. Rev. Minerva, vol. XI. Recuperado de: http://www.circulobellasartes.com/fich_minerva_articulos/Arte,__ genio__y__locura_(5815).pdf

Martín, O. (s.f.). Goya. Pinturas negras. Rescatado de: http://dialnet.unirioja.es/ servlet/dcfichero_articulo?codigo $=2248541$

Morales, J. (2001). La evaluación en el área de educación visual y plástica en la Educación Secundaria Obligatoria. Tesis doctoral. Universidad Autónoma de Barcelona. Bellaterra, Barcelona.

Morales, M. Cormino, F. (2007). El desequilibrio de la proporción. El genio maligno: Revista de Humanidades y Ciencias Sociales. No. 1. Recuperado de: http:// dialnet.unirioja.es/servlet/articulo?codigo $=2498129$

Morillo, R. Moreno, M. Rodríguez, M. (2009). La familia, la enfermedad, el dolor y la muerte en la obra pictórica de EdvardMunch. Cultura de los cuidados: Revista de enfermería y humanidades. (25), 29-35. Recuperado de: http:// dialnet.unirioja.es/servlet/articulo?codigo $=3035923$

Nitschack, H. (1991). La estética de la recepción. ARETE, III (2). Recuperado de: http:// ezproxybib.pucp.edu.pe/index.php/arete/article/viewFile/5065/5057

Pascale, P. (2005). ¿Dónde está la creatividad? Una aproximación al modelo de sistemas de MihalyCsikszentmihalyi. Arte, Individuo y Sociedad, XVII, 61-84. 
Peiry, L. (2006). La aventura del art brut. De la clandestinidad a la consagración. Genio y Delirio, Colección de Art Brut de Lausana. Círculo de Bellas artes. Madrid. Recuperado de: http://www.circulobellasartes.com/fich_libro/arch_ fich_libro_24.pdf

Politzer, G. (1975). Principios elementales de la filosofía. México: Ediciones de Cultura Popular.

Puente B, M. (2010) Arte y locura. Revista Anuario ICG-AGC. Recuperado de: http://www.grafoanalisis.com/Arte_y_Locura_.pdf

Rodríguez, A. (2004). Intento de contribución psicobiográfica de Salvador Dalí. Heterogénesis, (48). Recuperado de: http://redalyc.uaemex.mx/ $\mathrm{src} /$ inicio/ForazarDescargaArchivo.jsp?cvRev $=108 \& \mathrm{cvArt}=10804804 \&$ nom br e=Intento\%20de\%20contribuci\%F3n\%20psicobiogr\%E1fica\%20de\%20 Salvador\%20Dal\%ED.

Romo, M. (1998). Teorías implícitas y creatividad artística. Arte, Individuo y Sociedad, vol. X. Universidad Complutense. Madrid. Recuperado de: http:// revistas.ucm.es/index.php/ARIS/article/view/ARIS9898110011A/5961.

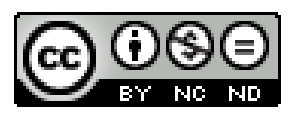

Este obra está bajo una licencia de Creative Commons ReconocimientoNoComercial-SinObraDerivada 4.0 Internacional. 